\title{
A Composite Contract for Coordinating a Supply Chain with Price and Effort Dependent Stochastic Demand
}

\author{
Yu-Shuang Liu, Yun Shang, and Hong-yan Su \\ School of Mathematics and Physics, Qingdao University of Science and Technology, Qingdao 266061, China \\ Correspondence should be addressed to Yu-Shuang Liu; qustlys@126.com
}

Received 25 January 2016; Accepted 9 June 2016

Academic Editor: Emilio Insfran

Copyright (C) 2016 Yu-Shuang Liu et al. This is an open access article distributed under the Creative Commons Attribution License, which permits unrestricted use, distribution, and reproduction in any medium, provided the original work is properly cited.

\begin{abstract}
As the demand is more sensitive to price and sales effort, this paper investigates the issue of channel coordination for a supply chain with one manufacturer and one retailer facing price and effort dependent stochastic demand. A composite contract based on the quantity-restricted returns and target sales rebate can achieve coordination in this setting. Two main problems are addressed: (1) how to coordinate the decentralized supply chain; (2) how to determine the optimal sales effort level, pricing, and inventory decisions under the additive demand case. Numerical examples are presented to verify the effectiveness of combined contract in supply chain coordination and highlight model sensitivities to parametric changes.
\end{abstract}

\section{Introduction}

Channel coordination via designing perfect contract is an important topic in supply chain management. It is well known that if both the manufacturer and the retailer maximize their own profits, double marginalization, a phenomenon first identified by Spengler [1], will prevail. That is, the retailer will order less than the integrated supply chain's optimal inventory level, which negatively affects the supply chain performance. A properly designed contract can completely eliminate the problem of double marginalization. That is, the supply chain contracts are used to drive the total expected profit of the decentralized supply chain toward that achieved under an integrated system. In this paper, we refer to this practice as supply chain coordination.

In the majority of supply chain contract literature, the retailer impacts sales only through his stocking decision, but in reality a retailer can spur sales through many different activities. Probably the first influential one is the retail price. When the retail price is given exogenously, contracts such as returns (buy-back), revenue sharing, quantity flexibility, and sales rebate have been shown to be successful in coordinating a two-echelon supply chain [2]. When the demand is sensitive to the retail price, the retailer is needed to decide the optimal retail price and order quantity jointly. Unfortunately, coordination is hard to achieve by the fact that the incentives to align the retailer's quantity decision may distort the retailer's price decision.

Apart from the retail price, the retailer's sales effort is also important in influencing demand. A retailer can hire more sales people, improve their training, increase advertising, provide attractive shelf space, and guide consumer purchases with sales personnel. All of those activities are costly. A conflict exists between the manufacturer and retailer, because those activities benefit both firms but are costly to only one. If the demand is considered only to be dependent on the retailer's sales effort, Cachon [2] demonstrates that both returns policy and sales rebate contract fail to coordinate a supply chain in this setting, because the retailer's optimal effort level is lower than that of the integrated supply chain under the buy-back contract, while the retailer exerts too much effort under the sales rebate contract.

As the demand is more sensitive to price and sales effort, retail price and sales effort are key decisions in retailing. Some literature such as [3-5] study the supply chain with the price and effort dependent demand; however, the demand is assumed to be deterministic. In this paper, we consider a stochastic demand for a product at the retailer during a single selling season that is price and effort dependent. If the retail price, sales effort, and order quantity are decision variables 
together, there is a lack of effective coordinating contracts in the literature. He et al. [6] have shown that coordination cannot be achieved by a single contract mechanism, for returns or target sales rebate contract alone. They find that only the properly designed returns policy with sales rebate and penalty contract are able to achieve channel coordination and lead to a Pareto improving win-win situation for supply chain members. Different from [6], we will transform full returns into quantity-restricted returns and sales rebate and penalty into target sales rebate. This composite contract also can achieve perfect coordination. The main idea behind this composite contract is to use the two distinctive contracts to align the retailer's three decisions with the optimal decisions of the centralized system. Consequently, in this paper, our analytical results lend insight into how a manufacturer should use quantity-restricted returns and target sales rebate provisions in a contract in order to coordinate the retailer who makes three decisions simultaneously. After that, we use an additive demand model to show that there exist the optimal pricing, sales effort, and ordering decisions uniquely in the centralized supply chain.

The paper is organized as follows. Section 2 provides a survey of related research on composite contracts. In Sections 3 and 4, we introduce the composite contract in detail, and then we present the basic models for a centralized and a decentralized supply chain under the price and effort dependent demand cases, respectively. We investigate the role of the composite contract for supply chain coordination and profit allocation. For the additive demand model, Section 5 proves that there exists the optimal effort-pricing-ordering joint decision uniquely and uses numerical example to illustrate our results. Section 6 provides concluding remarks.

\section{Related Literature on Composite Contracts}

Supply chain contracts have received much attention from researchers; comprehensive reviews of the supply chain contracting literature are provided by Cachon [2]. One of the commonly used supply chain contracts for short-life-cycle products is the returns policy, wherein the manufacturer agrees to buy back unsold goods from the retailer at a prespecified price that is less than the wholesale price. The main objective of the returns policy is to mitigate the risk of overstocking faced by the retailer, which is caused by the uncertain demand. Pasternack [7] is the first to study a returns contract, he demonstrates that returns policy (e.g., partial returns with full buy-back credit or full returns with partial buy-back credit) can achieve channel coordination with price-independent demand. Sales rebate is a converse of returns policy in that the manufacturer pays the retailer based on the retailer's sales performance. There are two common forms of channel rebates. One is linear rebate, in which the manufacturer pays the retailer a fixed rebate for each unit sold. The other form is target sales rebate, in which the retailer will be granted a rebate for each unit sold beyond a specified target level. As Taylor demonstrated in [8], a properly designed target sales rebate achieves channel coordination and a win-win outcome, while the linear rebate fails to coordinate when demand is not influenced by sales effort.

In contrast, there is a limited research on hybrid contracts. To fill this research gap, we investigate the role of some combined contracts for mitigating the double marginalization effect and improving supply chain performance. With regard to the retailer's decision-making behavior, Gan et al. [9] consider a supply chain with a risk-neutral supplier and a downside-risk-averse retailer and design a risk-sharing contract that offers the desired downside protection to the retailer. Interestingly, the contract they propose is a composite contract, which involves adding a return policy to the initial contract. Note that the return policy is different from that in Pasternack [7] in the sense that the amount of refundable inventory in their contract does not exceed a certain level. Wang and Webster [10] consider a supply chain with a riskneutral manufacturer and a loss-averse retailer. They identify a class of distribution-free coordinating contracts by combining gain/loss-sharing and buy-back contracts, which arbitrarily allocate the expected supply chain profit between the manufacturer and retailer.

Under the general stochastic demand, Xiong et al. [11] propose a composite contract based on the buy-back contract and quantity flexibility contract. They discuss its advantages over the buy-back contract and quantity flexibility contract in terms of coordination, profit allocation, and risk allocation. Liu et al. [12] also study a selling system consisting of one supplier and one retailer, which has a short life cycle, but its lead time of production is longer than its selling cycle; at the same time, its selling price is decreased gradually to the end customer under uncertain demand. They develop a two-period dynamic model to depict the above case and design a combined contract with markdown money and return policy to coordinate the channel.

When demand is influenced by retailer's sales effort, Taylor [8] designs a contract by combining a target rebate contract and a returns contract to achieve supply chain coordination and a win-win outcome. As retail pricing is an important vehicle to enhance supply chain revenue, Chiu et al. [13] show that a policy that combines the use of wholesale price, channel rebate, and returns (PRR) can coordinate a channel with both additive and multiplicative price-dependent demands. In fact, Chiu et al's contract is a hybrid of full returns and target sales rebate. That is, the manufacturer allows the retailer to return all the unsold products at the end of season.

He et al. [6] investigate the issue of channel coordination with a hybrid contract for a supply chain facing stochastic demand that is sensitive to both sales effort and retail price. Based on [6], we explore the fact that another composite contract also can achieve channel coordination in this setting.

\section{Model Assumptions and the Integrated Supply Chain}

Consider a supply chain model with one manufacturer $M$ and one retailer $R$. Let $p$ be the retail price, let $c$ be the production cost of manufacturer, let $v$ be the salvage value, and let $q$ be the retailer's order quantity. The retailer faces a random 
demand that is sensitive to both retail price and sales effort. To model retail effort, we suppose a single effort level $e$ which summarizes the retailer's activities and let $g(e)$ be the retailer's cost of exerting effort level $e$, where $g(0)=0, g^{\prime}(e)>0$, and $g^{\prime \prime}(e)>0 . X$ denotes the random demand during a short selling season, which is decreasing in price and increasing in effort. Given the price $p$ and the effort level $e, f(x \mid p, e)$ and $F(x \mid p, e)$ are the probability density function and distribution function. $S(p, e, q)$ is expected sales given the retail price, the effort level, and the stocking quantity; that is,

$$
S(p, e, q)=q-\int_{0}^{q} F(x \mid p, e) d x
$$

Then the expected left over inventory is $I(p, e, q)=q-$ $S(p, e, q)$.

At the beginning of the selling season, $M$ offers a contract to $R$, and then $R$, knowing the manufacturer's contract, determines the order quantity, the retail price, and effort level. The purpose of the manufacturer offering a composite contract to the retailer is to coordinate the supply chain and maximize the entire supply chain's profit. To do so, we start our analysis with the centralized supply chain. The integrated channel's profit is

$$
\pi(p, e, q)=p S(p, e, q)+v I(p, e, q)-c q-g(e) .
$$

In order to facilitate the analysis, (2) can be rearranged as follows:

$$
\begin{aligned}
\pi(p, e, q)= & p S(p, e, q)+v \int_{0}^{t} F(x \mid p, e) d x \\
& +v \int_{t}^{q} F(x \mid p, e) d x-c q-g(e) .
\end{aligned}
$$

Furthermore, there is no need to show that the integrated channel profit function is concave or unimodal. Let $\left(e^{*}, p^{*}, q^{*}\right)$ be the optimal decision for the centralized supply chain. The partial derivatives of $\pi(p, e, q)$ with respect to each of the decision variables are as follows:

$$
\begin{aligned}
\frac{\partial \pi(p, e, q)}{\partial e}= & p \frac{\partial S(p, e, q)}{\partial e}+v \int_{0}^{t} \frac{F(x \mid p, e)}{\partial e} d x \\
& +v \int_{t}^{q} \frac{F(x \mid p, e)}{\partial e} d x-g^{\prime}(e), \\
\frac{\partial \pi(p, e, q)}{\partial p}= & S(p, e, q)+p \frac{\partial S(p, e, q)}{\partial p} \\
& +v \int_{0}^{t} \frac{F(x \mid p, e)}{\partial p} d x \\
& +v \int_{t}^{q} \frac{F(x \mid p, e)}{\partial p} d x, \\
\frac{\partial \pi(p, e, q)}{\partial q}= & p \frac{\partial S(p, e, q)}{\partial q}+v F(q \mid p, e)-c .
\end{aligned}
$$

Setting these derivatives to zero, $\left(e^{*}, p^{*}, q^{*}\right)$ satisfy the following first-order optimality conditions:

$$
\begin{aligned}
\frac{\partial \pi\left(p^{*}, e^{*}, q^{*}\right)}{\partial e} & =\frac{\partial \pi\left(p^{*}, e^{*}, q^{*}\right)}{\partial p}=\frac{\partial \pi\left(p^{*}, e^{*}, q^{*}\right)}{\partial q} \\
& =0 .
\end{aligned}
$$

\section{The Decentralized Supply Chain under Composite Contract}

4.1. The Composite Contract. In this section, $M$ offers a composite contract, denoted by $C(w, t, r, b)$, by organically combining two popular contracts: returns policy and target sales rebate contract.

At the beginning of the selling season, $M$ makes four decisions: the unit wholesale price $w$, the target sales level $t$, the rebate value $r$ per unit sold beyond the threshold $t$, and the buy-back price $b$ for each unsold unit returned by $R$. For any unit of product sold by the retailer which exceeds target sales level, the retailer will be granted a rebate. But the quantity that can be returned to the manufacturer is restricted. More specific, if the actual sales are no greater than $t$, only the volume that exceeds the target level $t$ can be returned to the manufacturer with the buy-back price $b$. To the remaining unsold products, $R$ has no choice but to receive the salvage value $v$ per unit at the end of the selling season.

Clearly, above composite contract with four parameters is a hybrid of quantity-restricted returns contract and target sales rebate contract, which is similar in some sense to the one studied by Chiu et al. [13]. The only difference is to restrict quantities of returns, while in Chiu et al.'s contract the unsold products are full returns. As Chiu et al. said in [13], in the retailing industries such as Marathon Sport (Marathon Sport is one of the largest sportswear retailers in Hong Kong who sells multiple brands of sports apparels; different manufacturers such as Nike or Adidas offer different target sales rebate programs with different durations that vary between 1 and 2 months; Marathon Sport can earn a rebate value for each item only when Marathon Sport sells more than a prespecified sales target; to reduce the risk of overstocking because of the rebate program, Marathon Sport can return unsold items (up to a certain percentage of the order quantity) at the end of the season), it is a common practice to be provided with the returns and target sales rebate. On the other hand it also differs from He et al.s contract. The key difference between He et al's contract is that for quantity below target there is neither a penalty nor a buy-back and it is the retailer's responsibility. In addition, not only does the composite contract with quantity-restricted returns and target sales rebate help alleviate the double marginalization phenomenon, but also the contract parameters are free of demand function.

For any given composite contract $C(w, t, r, b), R$ has the objective of determining jointly the stocking quantity $q$, the unit selling price $p$, and the level of effort $e$ to maximize her expected profit. The target sales rebate contract is interesting only if it achieves supply chain coordination for $t \leq q$ [2]; 
we therefore assume that $t \leq q$ in the following model. The retailer's profit function under the composite contract is

$$
\begin{aligned}
\Pi_{R}^{c}(p, e, q, x)= & p(\min (q, x))+r(\min (q, x)-t)^{+} \\
& +b(q-\max (t, x))^{+}+v(t-x)^{+} \\
& -w q-g(e) .
\end{aligned}
$$

The expected revenue is

$$
\begin{aligned}
\pi_{R}^{c}(p, e, q)= & p S(p, e, q)+v \int_{0}^{t} F(x \mid p, e) d x \\
& +(b-r) \int_{t}^{q} F(x \mid p, e) d x-(w-r) q \\
& -r t-g(e) .
\end{aligned}
$$

Then,

$$
\begin{aligned}
\frac{\partial \pi_{R}^{c}(p, e, q)}{\partial e}= & p \frac{\partial S(p, e, q)}{\partial e}+v \int_{0}^{t} \frac{F(x \mid p, e)}{\partial e} d x \\
& +(b-r) \int_{t}^{q} \frac{F(x \mid p, e)}{\partial e} d x \\
& -g^{\prime}(e), \\
\frac{\partial \pi_{R}^{c}(p, e, q)}{\partial p}=S(p, e, q)+p \frac{\partial S(p, e, q)}{\partial p} & +v \int_{0}^{t} \frac{F(x \mid p, e)}{\partial p} d x \\
& +(b-r) \int_{t}^{q} \frac{F(x \mid p, e)}{\partial p} d x, \\
\frac{\partial \pi_{R}^{c}(p, e, q)}{\partial q}= & p \frac{\partial S(p, e, q)}{\partial q}+(b-r) F(q \mid p, e) \\
& -(w-r) .
\end{aligned}
$$

We now verify that the composite contract is capable of coordinating the supply chain. The composite contract designed by $M$ is said to coordinate the supply chain if it is able to entice the retailer to set their optimal decision as $\left(e^{*}, p^{*}, q^{*}\right)$. Thus, if the optimal solution $\left(e^{*}, p^{*}, q^{*}\right)$ for the integrated channel is to be adopted by the retailer, it must optimize their expected profit function $\pi_{R}^{c}(p, e, q)$, and hence it must satisfy the following first-order conditions:

$$
\begin{aligned}
\frac{\partial \pi_{R}^{c}\left(p^{*}, e^{*}, q^{*}\right)}{\partial e} & =\frac{\partial \pi_{R}^{c}\left(p^{*}, e^{*}, q^{*}\right)}{\partial p} \\
& =\frac{\partial \pi_{R}^{c}\left(p^{*}, e^{*}, q^{*}\right)}{\partial q}=0 .
\end{aligned}
$$

By comparing (4) with (8), we find that $\left(e^{*}, p^{*}, q^{*}\right)$ satisfies (9) only if $b^{*}$ and $r^{*}$ satisfy the certain conditions as follows:

$$
\begin{aligned}
& b^{*}=w-c+v, \\
& r^{*}=w-c .
\end{aligned}
$$

In other words, if (10) holds, the composite contract can coordinate the entire supply chain. It is significant that the parameters for coordination are not dependent on the stochastic demand function.

Now consider the allocation of channel profit. Substituting (10) into (7), the retailer's profit function given a coordinating composite contract is

$$
\pi_{R}^{c}\left(p^{*}, e^{*}, q^{*}\right)=\pi\left(p^{*}, e^{*}, q^{*}\right)-r t .
$$

Hence, the manufacturers profit function is

$$
\pi_{M}^{c}\left(p^{*}, e^{*}, q^{*}\right)=r t=(w-c) t .
$$

The manufacturer earns a profit margin for each unit up to the sales target $t$ and has a zero profit margin for each returned unit because $w-b-c+v=0$. In summary, we give the following proposition.

Proposition 1. The composite contract $C(w, t, r, b)$ based on quantity-restricted returns and target sales rebate can achieve channel coordinate if and only if the manufacturer sets contract parameters as $b^{*}=w-c+v$ and $r^{*}=w-c$, and the total supply chain profit can be split as $\left[(w-c) t, \pi\left(p^{*}, e^{*}, q^{*}\right)-(w-c) t\right]$ between the manufacturer and the retailer.

Notice that the optimal parameters for coordination in Proposition 1 are similar to He et al's model. This connection between the two contracts can be interpreted as follows.

In the decentralized supply chain, the retailer's profit depends on the location of $t<q$ with respect to the stochastic demand $X$. Specifically, the stochastic demand $X$ has the following three cases: (1) $t<X<q$, (2) $t<q<X$, and (3) $X<t<q$.

In case (1), since the final sales quantity $\min \{q, X\}$ is always greater than the target $t, M$ gives $R$ the rebate $r$ for each unit sold beyond $t$. At the same time, $R$ can fully return their unsold products to the manufacturer. In case (2), the retailer's sales quantity always exceeds the target $t$ and all the products are sold out. Hence, $R$ can only get the rebate from the manufacturer. Obviously, in these two cases they are equivalent. In case (3), as $X<t<q$, the retailer can never exceed the target. Thus, the retailer could not get rebate and can receive partly returns. In particular, only the volume beyond the target $t$ can be returned to $M$ with the buy-back price $b$. To the remaining unsold products, $R$ receives the salvage value $v$ per unit at the end of the selling season. As a consequence, the retailer's revenue of unsold products $q-x$ is $b(q-t)+v(t-X)$. With He et al's contract, the retailer can fully return their unsold products to the manufacturer and will need to pay the manufacturer a penalty: a payment of $r$ for each unit of unsold product below $t$. In this setting, the retailer's revenue of unsold products $q-X$ is $b(q-X)-r(t-X)$, which can be rearranged as $b(q-t)+(b-r)(t-X)$. Therefore, the retailer's revenue of unsold products $q-X$ is exactly the same if we set $b-r=v$.

Since we have established the same conditions for achieving coordination in the supply chain under a decentralized setting, however, it is realistic when this composite contract restricts the returns only for the quantity in excess of the sales 
target. Meanwhile, limiting the number of buy-backs is much easier to accept than a penalty. In fact, the quantity flexibility contract is also a kind of quantity-restricted returns in which the quantity that can be returned is restricted as $\delta q$ with the wholesale price. Webster and Weng [14] also consider quantity-restricted returns. From this point of view, the composite idea proposed in this paper seems more natural as an alternative contract under the price and effort dependent stochastic demand.

4.2. Pareto Improvement. In this section, we proceed to give the analytical condition for setting the sales target that can achieve Pareto improvement under the composite contract. The wholesale price contract usually can be used as a benchmark for comparing the channel performance. In order to induce the retailer to accept the composite contract, the manufacturer can choose an attractive sales target to achieve Pareto improvement so that both the manufacturer and the retailer can obtain a higher expected profit than that of under the wholesale price contract.

Under a wholesale price contract, the manufacturer charges the retailer $w$ for each unit, the retailer then decides his optimal effort level $e^{d}$, retailing price $p^{d}$, and order quantity $q^{d}$. The manufacturer's and the retailer's profit functions are

$$
\begin{aligned}
\pi_{R}^{d}(p, e, q, w)= & p S(p, e, q)+v I(p, e, q)-w q \\
& -g(e), \\
\pi_{M}^{d}(p, e, q, w)= & (w-c) q .
\end{aligned}
$$

The very basic aims of the retailer and the manufacturer would be to keep their profit higher than that in the wholesale price contract; that is,

$$
\begin{aligned}
& \pi_{R}^{c}\left(p^{*}, e^{*}, q^{*}\right) \geq \pi_{R}^{d}\left(p^{d}, e^{d}, q^{d}, w\right), \\
& \pi_{M}^{c}\left(p^{*}, e^{*}, q^{*}\right) \geq \pi_{M}^{d}\left(p^{d}, e^{d}, q^{d}, w\right) .
\end{aligned}
$$

From (14), the target sales level $t$ can be chosen in the following range:

$$
q^{d} \leq t \leq \frac{\pi\left(p^{*}, e^{*}, q^{*}\right)-\pi_{R}^{d}\left(p^{d}, e^{d}, q^{d}, w\right)}{w-c}
$$

If (15) holds, the coordinating composite contract can yield a higher expected profit for both the manufacturer and the retailer than the equilibrium wholesale price contract. In other words, the manufacturer can set the target level $t$ by (15). If the target $t$ reaches the left boundary, the manufacturer's revenue under the composite contract is his income in the wholesale price. With the increase of $t$, the manufacturer's profit is increasing, whereas the retailer's profit is decreasing. If the target $t$ reaches its upper bound, the retailer's revenue reduces to the profit of the wholesale price contract.

\section{Optimal Solutions and Numerical Analysis}

5.1. The Optimal Decisions under the Additive Demand Model. From Section 4, we know that if the manufacturer offers above composite contract, the retailer will choose the integrated supply chain's optimal decisions. Therefore, we will use the integrated supply chain to derive the optimal effort level $e^{*}$, pricing $p^{*}$, and stocking $q^{*}$.

Because the stochastic demand is sensitive to both retail price and sales effort, only the additive-error/linear-demand function will be discussed $[6,15]$. Specifically, the random single-period total demand $X$ is of the form

$$
X=y(p, e)+\varepsilon, \quad y(p, e)=\alpha-\beta p+k e,
$$

where $\alpha, \beta, k>0$. That is, the actual demand is the summation of the deterministic function and the stochastic factor. $y(p, e)$ is modeled using the downward-sloping linear function with respect to both price and sales effort, where $\alpha$ is the primary demand when both price and effort are set at zero, $\beta$ is the price sensitivity of demand, and $k$ is the sales effort sensitivity of demand. $\varepsilon$ is a random variable defined on the range $[A, B]$ with $\operatorname{PDF} \phi(\cdot)$ and $\operatorname{CDF} \Phi(\cdot)$. The retailer's sales effort cost is assumed as an increasing and convex function of sales effort $e$, defined as $g(e)=\mu e^{2} / 2$, where $\mu(\mu>0)$ is a constant, called sales effort cost parameter. Such a quadratic cost function is commonly used in previous literature. The following mild assumptions are necessary for obtaining equilibrium solutions.

Assumption 2. One has $\beta>k^{2} / \mu$.

Assumption 3. The distribution of the random variable $\varepsilon$ has an increasing failure rate (IFR) property: $h(\cdot)=\phi(\cdot) /(1-\Phi(\cdot))$ is increasing in $x$.

Defining the stocking factor $z$ as $z=q-y(p, e)$, it was introduced by [15] and widely used by $[6,16]$ as a decision variable instead of $q$. Then the centralized expected profit is written as follows:

$$
\begin{aligned}
\pi(p, e, z)= & (p-c)(y(p, e)+z)-(p-v) \Lambda(z) \\
& -g(e)
\end{aligned}
$$

where $\Lambda(z)=\int_{A}^{z}(z-u) \phi(u) d u$ represents the expected number of leftovers. The objective is to find the optimal $e^{*}, p^{*}$, and $z^{*}$ that maximize $\pi(p, e, z)$, stated in the following proposition.

Proposition 4. For the centralized supply chain and any given stocking factor $z(A \leq z \leq B)$, then

(1) the unique best response effort level $e^{*}$ is given by

$$
e^{*}=e(p)=\frac{k(p-c)}{\mu}
$$


(2) if $\beta>k^{2} / \mu$, the unique best response price $p^{*}$ is given by

$$
p^{*}=p(z)=\frac{\alpha+c\left(\beta-k^{2} / \mu\right)+z-\Lambda(z)}{2 \beta-k^{2} / \mu} ;
$$

(3) if $\beta>k^{2} / \mu$ and $\varepsilon$ has IFR, then the retailer's best response stocking factor $z^{*}$ is uniquely determined as the solution of

$$
\Phi(z)=\frac{\alpha-c \beta+z-\Lambda(z)}{\alpha-c \beta+(c-v)\left(2 \beta-k^{2} / \mu\right)+z-\Lambda(z)} .
$$

Proof. First, for any given $z$ and $p$, we take the partial derivative of (17) with respect to $e$ and get

$$
\begin{gathered}
\frac{\partial \pi(p, e, z)}{\partial e}=(p-c) \frac{\partial y(p, e)}{\partial e}-g^{\prime}(e), \\
\frac{\partial^{2} \pi(p, e, z)}{\partial e^{2}}=(p-c) \frac{\partial^{2} y(p, e)}{\partial e^{2}}-g^{\prime \prime}(e) .
\end{gathered}
$$

Since $\partial^{2} \pi(p, e, z) / \partial e^{2}<0, \partial \pi(p, e, z) / \partial e=0$ implies that $e^{*}=e(p)=k(p-c) / \mu$. Substituting (18) into (17):

$$
\begin{aligned}
\pi\left(p, e^{*}, z\right)= & (p-c)\left(y\left(p, e^{*}\right)+z\right)-(p-v) \Lambda(z) \\
& -g\left(e^{*}\right) .
\end{aligned}
$$

Second, for any given $z$, we want to derive $p^{*}$ which maximizes (22). By the chain rule, we have

$$
\frac{d \pi\left(p, e^{*}(p), z\right)}{d p}=\frac{\partial \pi\left(p, e^{*}, z\right)}{\partial e^{*}} \frac{d e^{*}}{d p}+\frac{\partial \pi\left(p, e^{*}, z\right)}{\partial p} .
$$

Since $e^{*}$ is the unique maximum value of $\pi(p, e, z)$, the first term $\partial \pi\left(p, e^{*}, z\right) / \partial e^{*}$ is 0 . Thus,

$$
\begin{aligned}
\frac{d \pi\left(p, e^{*}(p), z\right)}{d p}= & \alpha+c\left(b-\frac{k^{2}}{\mu}\right)+z-\Lambda(z) \\
& -\left(2 \beta-\frac{k^{2}}{\mu}\right) p .
\end{aligned}
$$

From $d \pi\left(p, e^{*}(p), z\right) / d p=0$, (19) is given. Meanwhile, if $\beta>k^{2} / \mu, d \pi\left(p, e^{*}(p), z\right) / d p>0$ for all $p^{*}<p(z)$ and $d \pi\left(p, e^{*}(p), z\right) / d p<0$ for all $p^{*}>p(z)$. So $p^{*}$ is the unique maximum value of $\pi\left(p, e^{*}(p), z\right)$.

Finally, we will prove that $z^{*}$ exists uniquely. Substituting $p^{*}$ into (22):

$$
\begin{aligned}
\pi\left(p^{*}, e^{*}, z\right)= & \left(p^{*}-c\right)\left(y\left(p^{*}, e^{*}\right)+z\right) \\
& -\left(p^{*}-v\right) \Lambda(z)-g\left(e^{*}\right) .
\end{aligned}
$$

By the chain rule, we have

$$
\begin{aligned}
\frac{d \pi\left(p^{*}, e^{*}, z\right)}{d z}= & \frac{\partial \pi\left(p^{*}, e^{*}, z\right)}{\partial e^{*}} \frac{d e^{*}}{d z} \\
& +\frac{\partial \pi\left(p^{*}, e^{*}, z\right)}{\partial p^{*}} \frac{d p^{*}}{d z} \\
& +\frac{\partial \pi\left(p^{*}, e^{*}, z\right)}{\partial z} .
\end{aligned}
$$

Likewise, the first and second terms are 0 :

$$
\begin{aligned}
\frac{d \pi\left(p^{*}, e^{*}, z\right)}{d z} & =p^{*}-c-\left(p^{*}-c\right) \Phi(z) \\
& =\frac{g(z)}{2 \beta-k^{2} / \mu},
\end{aligned}
$$

where $g(z)=\alpha-\beta c+z-\Lambda(z)-\left[\alpha-\beta c+(c-v)\left(2 \beta-k^{2} / \mu\right)+\right.$ $z-\Lambda(z)] \Phi(z)$.

Under Assumption 2, we have $2 \beta-k^{2} / \mu>0$, which implies that the optimal $z^{*}$ satisfies $g\left(z^{*}\right)=0$. We therefore give (20). Such a $z^{*}$ always exists in the support interval $[A, B]$ of $\varepsilon$, since $g(z)$ is continuous in $[A, B]$, and $g(A)=\alpha-\beta c+A>$ $0, g(B)=-(c-v)\left(2 \beta-k^{2} / \mu\right)<0$. To verify the uniqueness of $z^{*}$, we need

$$
\begin{aligned}
& g^{\prime}(z)=[1-\Phi(z)]\{1-\Phi(z)-h(z) \\
& \left..\left[\alpha-\beta c+(c-v)\left(2 \beta-\frac{k^{2}}{\mu}\right)+z-\Lambda(z)\right]\right\}, \\
& g^{\prime \prime}(z)=-h(z) g^{\prime}(z)+[1-\Phi(z)]\left\{-\phi(z)-h^{\prime}(z)\right. \\
& \cdot\left[\alpha-\beta c+(c-v)\left(2 \beta-\frac{k^{2}}{\mu}\right)+z-\Lambda(z)\right] \\
& -h(z)[1-\Phi(z)]\} .
\end{aligned}
$$

According to Assumptions 2 and $3, g^{\prime \prime}(z)<0$ at $g^{\prime}(z)=0$, which implies that $g(z)$ is a unimodal function in $[A, B]$, which guarantees the uniqueness of $z^{*}$.

5.2. Numerical Analysis. Given the central objective of the paper, this section operates with the integrated supply chain and the wholesale price contract to derive the optimal solutions. For notational convenience, let $z^{*}, p^{*}, e^{*}$, and $q^{*}$ denote the optimal decisions under the centralized supply chain, and $\pi$ denotes the integrated channel profit. Let $z^{d}, p^{d}, e^{d}$, and $q^{d}$ be the retailer's decisions at equilibrium under the wholesale price contract. $\pi_{M}^{d}$ and $\pi_{R}^{d}$ are the respective profits of the manufacturer and retailer given that the manufacturer charges $w$ and the retailer sets $p^{d}, e^{d}$, and $q^{d}$. As a result, $\pi^{d}$ denotes the aggregate profit of the decentralized system; that is, $\pi^{d}=\pi_{R}^{d}+\pi_{M}^{d}$. We set the parameter values as $\alpha=50, \mu=10, c=5$, and $v=1$. The random perturbation on the demand, $\varepsilon$, is assumed to follow the uniform distribution on $[0,2]$.

In Table 1, the values of $w$ are fixed at $w=10$; then Table 1 summaries, at equilibrium, the retailer's optimal decisions under centralized and decentralized decision models by varying the values of $\beta$ and $k$, respectively. The retailer's optimal stocking factor and sales effort level under the wholesale price contract are less than that in the centralized channel model, but the optimal selling price changes in an opposite way. 
TABLE 1: The effect of $\beta$ and $k$ on the optimal decisions and profit.

\begin{tabular}{lccccccccccccc}
\hline & $z^{*}$ & $p^{*}$ & $e^{*}$ & $q^{*}$ & $\pi$ & $z^{d}$ & $p^{d}$ & $e^{d}$ & $q^{d}$ & $\pi_{R}^{d}$ & $\pi_{M}^{d}$ & $\pi^{d}$ & $t$ \\
\hline$\beta=2, k=2$ & 1.48 & 16.37 & 2.27 & 23.29 & 230.51 & 1.36 & 18.58 & 1.72 & 17.63 & 128.42 & 88.16 & 216.57 & $17.63 \sim 20.42$ \\
$\beta=3, k=2$ & 1.23 & 11.40 & 1.28 & 19.59 & 113.25 & 0.96 & 13.70 & 0.74 & 11.34 & 36.29 & 56.68 & 92.97 & $11.34 \sim 15.39$ \\
$\beta=3, k=3$ & 1.27 & 12.03 & 2.11 & 21.51 & 124.51 & 1.01 & 14.07 & 1.22 & 12.46 & 39.94 & 62.31 & 102.25 & $12.46 \sim 16.91$ \\
$\beta=3, k=1$ & 1.20 & 11.07 & 0.61 & 18.59 & 107.42 & 0.93 & 13.51 & 0.35 & 10.75 & 34.40 & 53.76 & 88.16 & $10.75 \sim 14.60$ \\
\hline
\end{tabular}

TABLE 2: The effect of $w$ on the optimal decisions and profit.

\begin{tabular}{lccccccccccccc}
\hline & $z^{*}$ & $p^{*}$ & $e^{*}$ & $q^{*}$ & $\pi$ & $z^{d}$ & $p^{d}$ & $e^{d}$ & $q^{d}$ & $\pi_{R}^{d}$ & $\pi_{M}^{d}$ & $\pi^{d}$ & $t$ \\
\hline$w=8$ & 1.48 & 16.37 & 2.27 & 23.29 & 230.51 & 1.42 & 17.7 & 1.94 & 19.9 & 165.8 & 59.7 & 225.5 & $19.9 \sim 21.57$ \\
$w=10$ & 1.48 & 16.37 & 2.27 & 23.29 & 230.51 & 1.36 & 18.58 & 1.72 & 17.63 & 128.42 & 88.16 & 216.57 & $17.63 \sim 20.42$ \\
$w=12$ & 1.48 & 16.37 & 2.27 & 23.29 & 230.51 & 1.30 & 19.47 & 1.49 & 15.36 & 95.68 & 107.49 & 203.17 & $15.36 \sim 19.26$ \\
\hline
\end{tabular}

Hence, the aggregate profit of the decentralized system $\pi^{d}$ is less than the integrated channel profit $\pi$. Further, Table 1 also gives the range of the target sales level $t$. If the manufacturer sets $t$ the same as Table 1 , the composite contract can yield a higher expected profit for both the manufacturer and the retailer than the equilibrium wholesale price contract. For example, at $t=19$, we have

$$
\begin{aligned}
\pi_{R}^{c}\left(p^{*}, e^{*}, q^{*}\right) & =135.51>\pi_{R}^{d}\left(q^{d}, p^{d}, e^{d}, w\right) \\
& =128.42 \\
\pi_{M}^{c}\left(p^{*}, e^{*}, q^{*}\right) & =95>\pi_{M}^{d}\left(q^{d}, p^{d}, e^{d}, w\right)=88.16 .
\end{aligned}
$$

In Table 2, we increase the manufacturer's wholesale price from 8 to 12 while keeping $\beta=2$ and $k=2$, respectively. It is shown that the retailer's equilibrium order quantity $q^{d}$ and their expected profit $\pi_{R}^{d}$ under the wholesale price contract decreases as $w$ increases. This is intuitive; thus, we will mainly give the effect of $w$ on the sales target $t$. The lower limit of the sales target $t$ is the retailer's equilibrium order quantity under the wholesale price contract. Since the target $t$ reaches its upper bound, the retailer's revenue reduces to the profit of the wholesale price contract. That is to say, the lower and upper bound of $t$ decrease as $w$ increases. However, the range of $t$ would become larger with the increase of $w$. From Proposition 1, the total supply chain profit can be split arbitrarily between the manufacturer and the retailer by varying $t$ for a given $w$. Hence, the manufacturer, as the Stackelberg leader, can raise his expected revenue by increasing the wholesale price $w$. On the other hand, according to our demand model, $p^{d}$ must satisfy $\alpha-\beta p \geq 0$, so the manufacturer could not set $w$ arbitrarily.

Because we consider an additive demand model which is a function of the retail price $p$ and the sales effort $e$, the price sensitivity of demand $\beta$ and the sales effort sensitivity of demand $k$ are two major factors which affect market demand. In order to properly evaluate the effect of one parameter on the equilibrium results, it is necessary to isolate it from other parameters by keeping other parameters constant. As a result, Figure 1 describes the effect of $\beta$ on the optimal decisions with fixed $k=2$, and Figure 2 describes the effect of $k$ on the optimal decisions with fixed $\beta=2$. We observe by

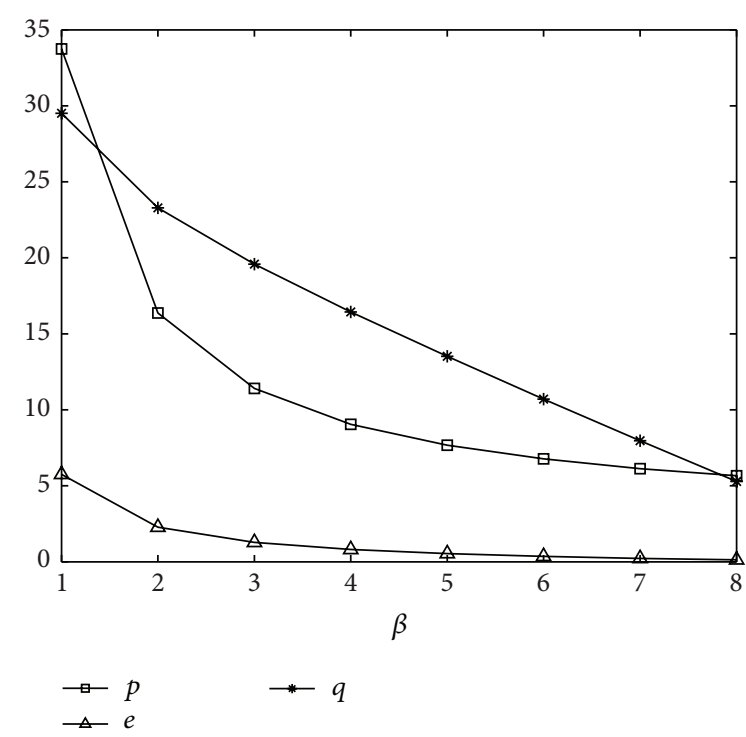

Figure 1: The effect of $\beta$ on the optimal decisions.

comparison that the retailer's optimal decisions are decreasing in $\beta$, while the retailer's optimal decisions are increasing in $k$. Figures 3 and 4 explore the effect of $\beta$ and $k$ on the target sales level $t$. From Figure 3, the target sales level $t$ becomes lower with the increase of $\beta$, but the range of $t$ becomes greater. As shown in Figure 4, the target sales level $t$ is increasing in $k$; however, the range of $t$ changes little. Figures 3 and 4 indicate that the parameter $\beta$ has greater flexibility than $k$ in splitting the total supply chain profit between the manufacturer and the retailer.

\section{Conclusion}

As demand becomes price and effort dependent, a key question is whether the contracts that coordinate the retailers order quantity also coordinate the retailers pricing and effort level. As a way to improve the coordination between the manufacturer and the retailer, there is an increasing interest in examining what type of supply contracts can be used to achieve channel coordination in the sense that each supply 


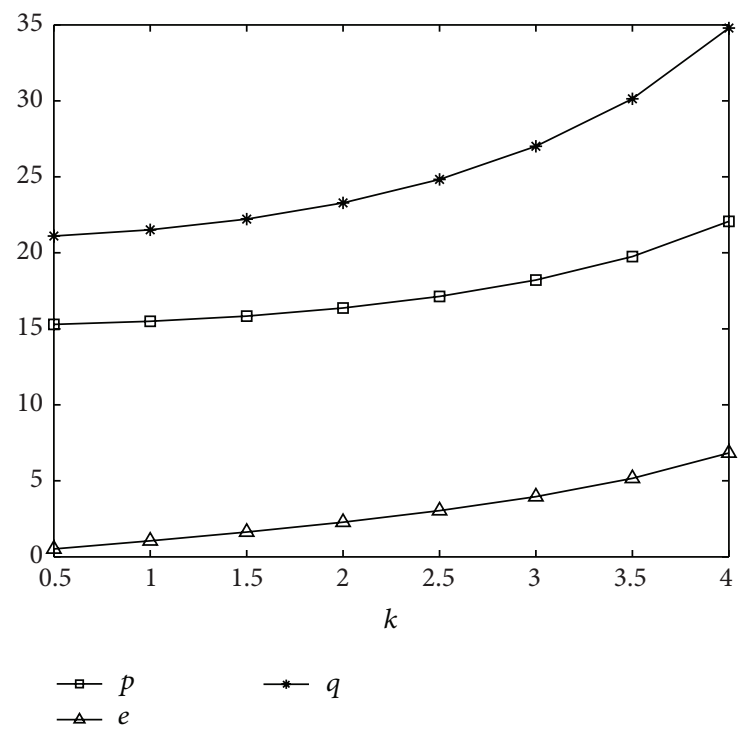

Figure 2: The effect of $k$ on the optimal decisions.

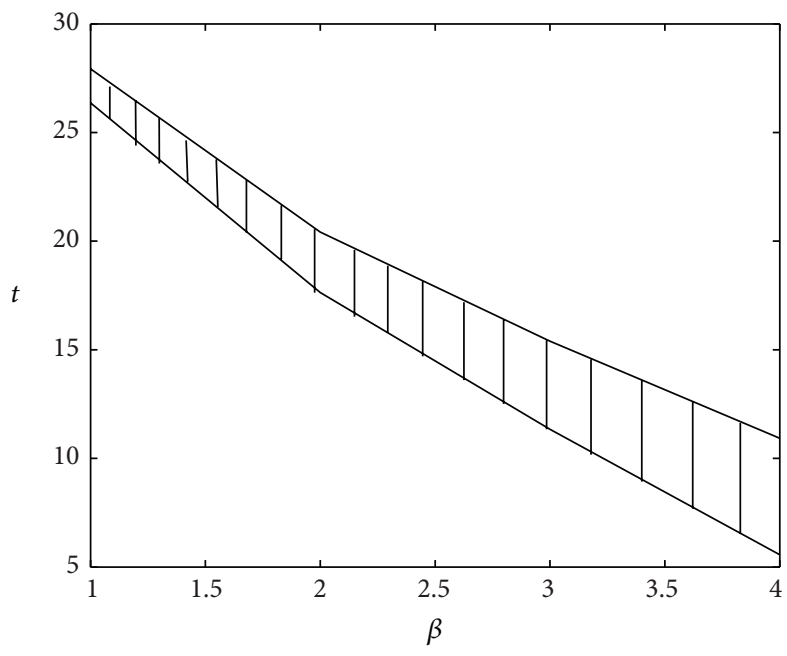

Figure 3: The effect of $\beta$ on the target sales level $t$.

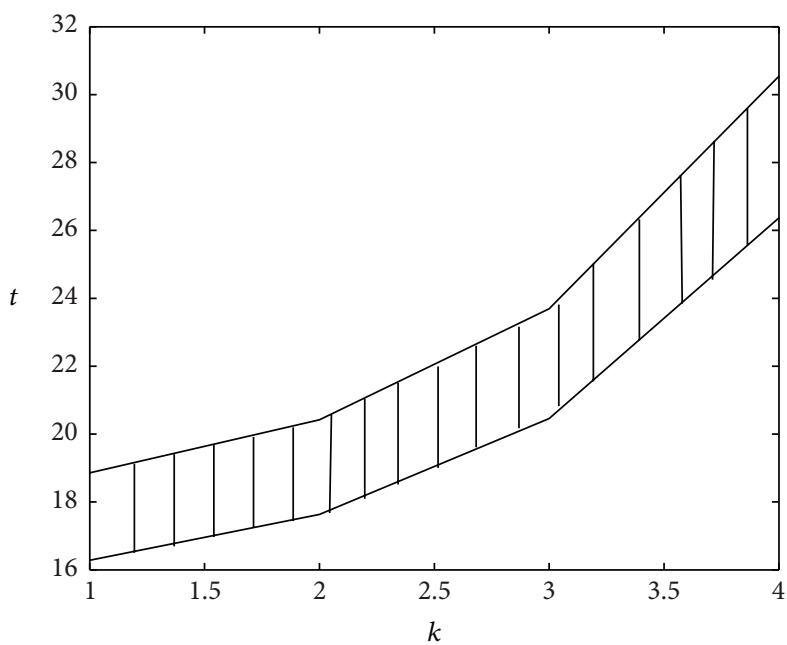

FIGURE 4: The effect of $k$ on the target sales level $t$. chain partner's objective becomes aligned with the supply chain's objective. In this paper, we show that there exists a composite contract that can achieve coordination when the random demand is sensitive to both retail price and sales effort. Then a properly designed target sales rebate contract and partial returns contract can achieve channel coordination (i.e., maximizes the profitability of the entire supply chain of both manufacturer and retailer) and win-win (i.e., both parties are made better off). One important feature worth noting is that the contract parameters for coordination in the composite contract are independent of the stochastic demand distribution.

As a future research direction, it is interesting to explore the composite contract in coordinating a supply chain with price-dependent demand and risk sensitive agents together. It will also be interesting to investigate the performance of the composite contract in considering strategic customer behavior.

\section{Competing Interests}

The authors declare that they have no competing interests.

\section{Acknowledgments}

This work is supported by Science and Technology Program of Qingdao, China (Grant no. 14-2-4-56-jch).

\section{References}

[1] J. J. Spengler, "Vertical integration and antitrust policy," Journal of Political Economy, vol. 58, no. 4, pp. 347-352, 1950.

[2] G. P. Cachon, "Supply chain coordination with contracts," Working Paper, University of Pennsylvania, Philadelphia, Pa, USA, 2002.

[3] B. C. Giri, S. Bardhan, and T. Maiti, "Coordinating a twoechelon supply chain through different contracts under price and promotional effort-dependent demand," Journal of Systems Science and Systems Engineering, vol. 22, no. 3, pp. 295-318, 2013.

[4] D. D. Wu, "Bargaining in supply chain with price and promotional effort dependent demand," Mathematical and Computer Modelling, vol. 58, no. 9-10, pp. 1659-1669, 2013.

[5] J. H. Gao, H. S. Han, L. T. Hou, and H. Y. Wang, "Pricing and effort decisions in a closed-loop supply chain under different channel power structures," Journal of Cleaner Production, vol. 112, part 3, pp. 2043-2057, 2016.

[6] Y. He, X. Zhao, L. D. Zhao, and J. He, "Coordinating a supply chain with effort and price dependent stochastic demand," Applied Mathematical Modelling, vol. 33, no. 6, pp. 2777-2790, 2009.

[7] B. A. Pasternack, "Optimal pricing and return policies for perishable commodities," Marketing Science, vol. 4, no. 2, pp. $166-176,1985$.

[8] T. A. Taylor, "Supply chain coordination under channel rebates with sales effort effects," Management Science, vol. 48, no. 8, pp. 992-1007, 2002.

[9] X. Gan, S. P. Sethi, and H. Yan, "Channel coordination with a risk-neutral supplier and a downside-risk-averse retailer," Production and Operations Management, vol. 14, no. 1, pp. 80-89, 2005. 
[10] C. X. Wang and S. Webster, "Channel coordination for a supply chain with a risk-neutral manufacturer and a loss-averse retailer," Decision Sciences, vol. 38, no. 3, pp. 361-389, 2007.

[11] H. C. Xiong, B. T. Chen, and J. X. Xie, "A composite contract based on buy back and quantity flexibility contracts," European Journal of Operational Research, vol. 210, no. 3, pp. 559-567, 2011.

[12] B. Liu, J. Chen, S. F. Liu, and R. Zhang, "Supply-chain coordination with combined contract for a short-life-cycle product," IEEE Transactions on Systems, Man, and Cybernetics Part A: Systems and Humans, vol. 36, no. 1, pp. 53-61, 2006.

[13] C.-H. Chiu, T.-M. Choi, and C. S. Tang, "Price, rebate, and returns supply contracts for coordinating supply chains with price-dependent demands," Production and Operations Management, vol. 20, no. 1, pp. 81-91, 2011.

[14] S. Webster and Z. K. Weng, "A risk-free perishable item returns policy," Manufacturing \& Service Operations Management, vol. 2, no. 1, pp. 100-106, 2000.

[15] N. C. Petruzzi and M. Dada, "Pricing and the newsvendor problem: a review with extensions," Operations Research, vol. 47, no. 2, pp. 183-194, 1999.

[16] F. J. Arcelus, R. Gor, and G. Srinivasan, "Price, rebate and order quantity decisions in a newsvendor framework with rebatedependent recapture of lost sales," International Journal of Production Economics, vol. 140, no. 1, pp. 473-482, 2012. 


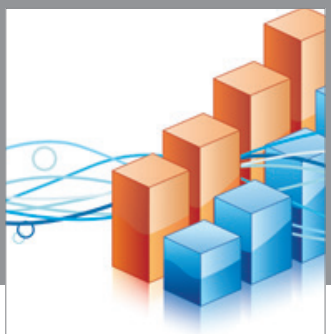

Advances in

Operations Research

vatem alat4

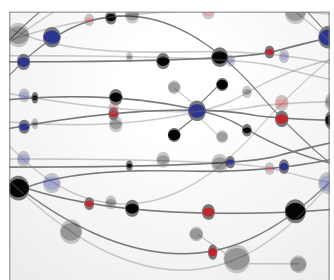

\section{The Scientific} World Journal
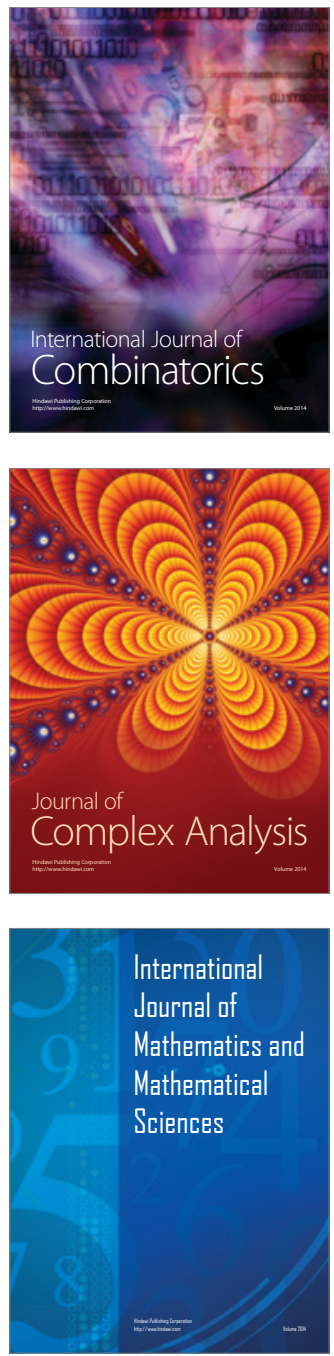
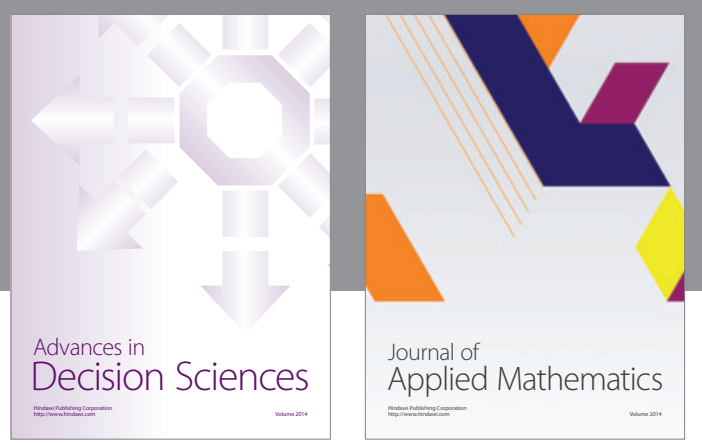

Algebra

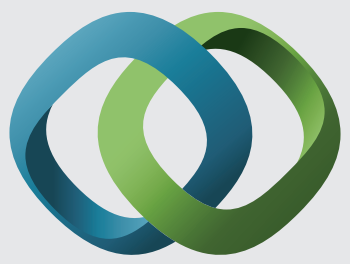

\section{Hindawi}

Submit your manuscripts at

http://www.hindawi.com
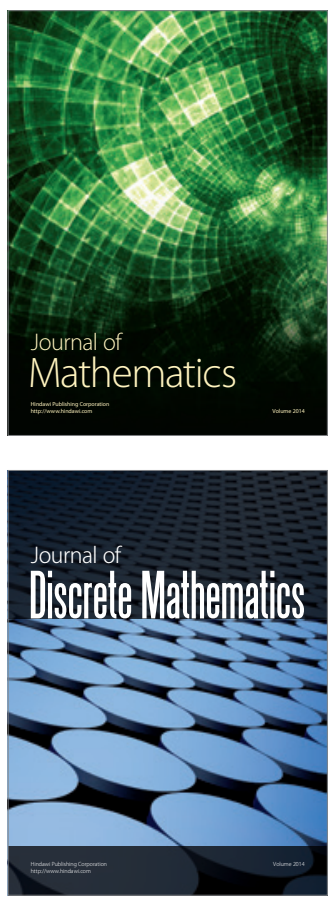

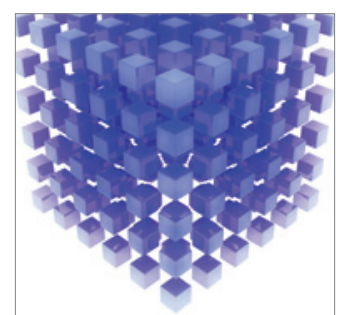

Mathematical Problems in Engineering
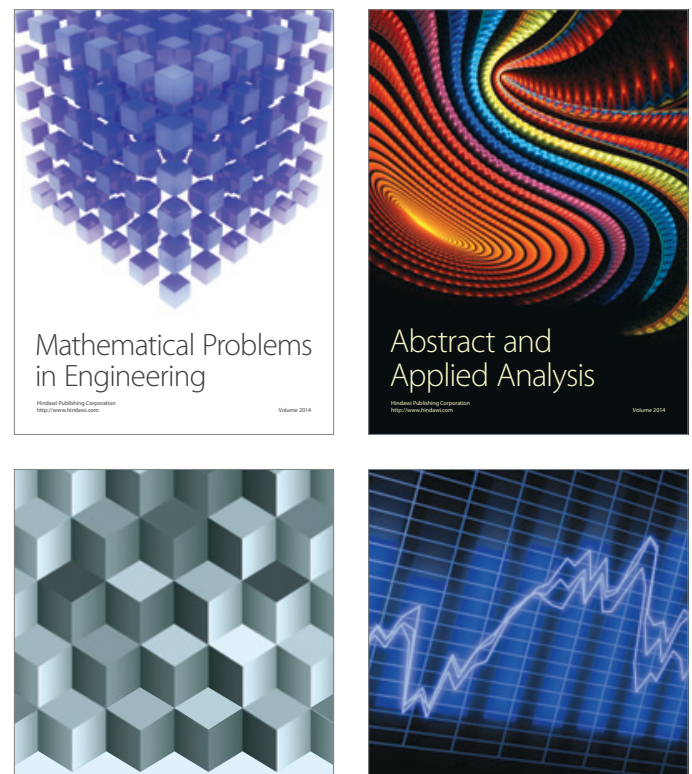

Journal of

Function Spaces

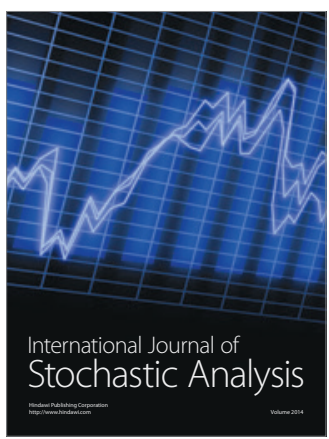

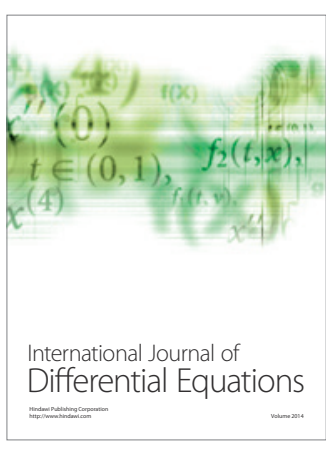
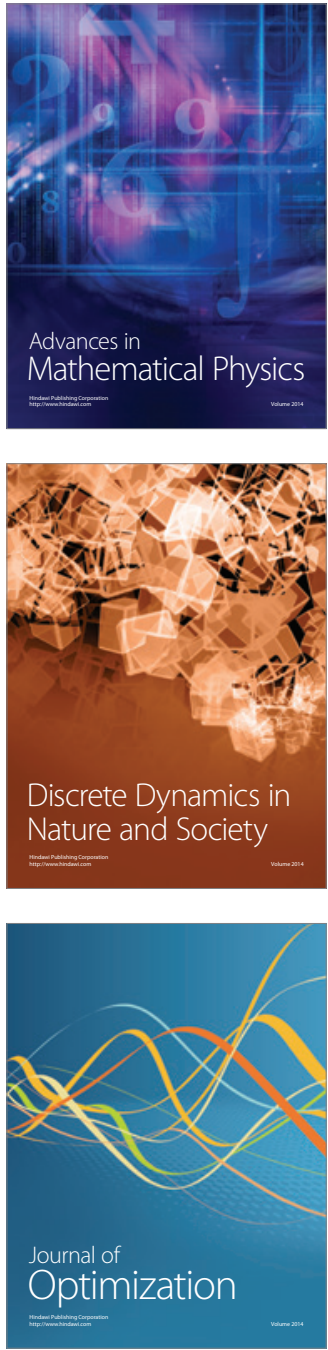